Revista Destaques Acadêmicos, Lajeado, v. 9, n. 3, 2017. ISSN 2176-3070

DOI: http://dx.doi.org/10.22410/issn.2176-3070.v9i3a2017.1328

www.univates.br/revistas

\title{
O AMBIENTE DE CUIDADO EM UTI NEONATAL: A PERCEPÇÃO DOS PAIS E DA EQUIPE DE SAÚDE
}

\author{
Paula Michele Lohmann ${ }^{1}$, Eduardo Périco ${ }^{2}$, Luis Felipe Pissaia ${ }^{3}$, \\ Arlete Eli Kunz da Costa ${ }^{4}$, Claudete Moreschi ${ }^{5}$
}

\begin{abstract}
Resumo: O estudo objetivou conhecer a percepção de pais e equipe de saúde sobre o cuidado prestado à criança internada em uma Unidade de Terapia Intensiva Neonatal (UTIN) de um hospital de médio porte localizado no interior do Rio Grande do Sul. A pesquisa foi descritiva e exploratória, com abordagem qualitativa. Os informantes da pesquisa foram nove pais de recém-nascidos internados em uma UTIN e 19 profissionais de saúde desta unidade, estes foram entrevistados e realizado análise de conteúdo temática segundo Bardin para a construção das temáticas. Em relação às percepções dos pais, os principais resultados surgidos foram sobre as orientações recebidas no momento da internação, o prognóstico e os procedimentos, na sua maioria, orientados pelos médicos plantonistas e pela enfermagem. Os principais dados obtidos com a equipe de saúde primeiramente foram em relação à percepção sobre o ambiente e em relação à permanência dos pais na unidade, como também as facilidades e dificuldades encontradas ao orientar os pais. $\mathrm{O}$ ambiente de cuidado, desenvolvimento inicial da criança, a UTIN, deverá estar pautado no cuidado integral a ele e sua família, auxiliando na formação do vínculo entre eles.
\end{abstract}

Palavras-chave: Meio Ambiente. Cuidado do Lactente. Equipe de Enfermagem. Pais.

1 Enfermeira. Mestre em Ambiente e Desenvolvimento. Universidade do Vale do Taquari Univates. paulalohmann@univates.br

2 Doutor em Ecologia. Universidade do Vale do Taquari - Univates. perico@univates.br

3 Enfermeiro. Mestrando em Ensino. Universidade do Vale do Taquari - Univates. lpissaia@universo.univates.br

4 Enfermeira. Doutora em Ambiente e Desenvolvimento. Universidade do Vale do Taquari Univates. arlete.costa@univates.br

5 Enfermeira. Doutora em Ambiente e Desenvolvimento. Universidade do Vale do Taquari Univates.clau_moreschi@yahoo.com.br 


\section{INTRODUÇÃO}

O ambiente da Unidade de Terapia Intensiva Neonatal (UTIN) ao mesmo tempo em que fornece tecnologias avançadas pode causar impacto às necessidades físicas e psicológicas destes recém-nascidos, sua família e para equipe que exerce seu trabalho. Neste local notamos que os ruídos são contínuos pelos alarmes de monitores, bombas de infusão e pela necessidade de luz sempre acesa, ocasionando a indiferença entre dia e noite, proporcionando estafa para todos os envolvidos neste processo de cuidado (OLIVEIRA et al., 2017).

A UTI Neonatal é o local destinado ao tratamento de bebês pré-termos que nascem com algum problema. Para alguns a prematuridade é uma das causas de internação de bebês que nascem em uma idade gestacional de 26 a 28 semanas, por exemplo, pesando de 750 a 1.000 gramas e que necessitam de um tempo de internação prolongado, para crescer e capacitar a sua respiração, tempo esperado para que possam ir para casa com os pais (LOPES, 2017).

O neonato em UTIN está vulnerável e depende do ambiente para que consiga manter uma organização fisiológica e de comportamento (TOLDO et al., 2017). Para os pais a internação pode ter tanto o significado de vida e segurança pela oferta dos mais avançados recursos que mantém o seu filho vivo, como pode também evocar sentimentos negativos como o medo e o desespero por visualizarem o sofrimento do filho e estarem impotentes a esta situação (OLIVEIRA; CRUZ, 2017).

Neste sentido, o estudo objetivou conhecer a percepção de pais e equipe de saúde sobre o cuidado prestado à criança internada em uma Unidade de Terapia Intensiva Neonatal (UTIN) de um hospital de médio porte localizado no interior do Rio Grande do Sul.

\section{MÉTODO}

A pesquisa é de campo, do tipo exploratório e descritivo, com abordagem qualitativa. A pesquisa foi desenvolvida em uma unidade de terapia intensiva neonatal de um hospital de médio porte do interior do estado do Rio Grande do Sul, este caracteriza-se por ser uma instituição filantrópica. A Unidade de Terapia Intensiva Pediátrica e Neonatal, objeto de estudo, conta com sete leitos, sendo dois leitos para internação pediátrica e cinco leitos para internação neonatal.

A coleta de dados ocorreu com dois grupos, um integrado por pais de RN internados na UTIN, sendo o critério de inclusão deste grupo, pais com idade superior a 18 anos, com recém-nascidos prematuros que estivessem internados na UTI Neonatal no período de no mínimo um mês; e o segundo grupo integrado pela equipe de saúde que trabalha na UTIN, que deveriam ter um tempo mínimo de seis meses de trabalho na UTIN da instituição. A coleta de dados ocorreu no período de outubro e novembro de 2010. 
O instrumento para coleta de coleta de dados, foram questionários um para os pais e outro para a equipe de saúde. Os dois questionários tiveram questões fechadas para caracterização dos informantes da pesquisa e questões norteadoras. O contato com os informantes foi agendado previamente, após autorização da instituição hospitalar e aprovação do Comitê de Ética e Pesquisa da Univates, conforme protocolo 123/10.

A análise dos dados para caracterização dos informantes da pesquisa foi por meio da análise descritiva por frequência. As questões norteadoras foram analisadas por meio da Análise de Conteúdo de Bardin (2011). Os informantes da pesquisa foram identificados, os pais com a letra $\mathrm{P}$ e número conforme ordem da entrevista. Para a equipe de saúde, a letra $\mathrm{E}$, e número conforme a ordem da entrevista.

\section{RESULTADOS E DISCUSSÃO}

\section{Caracterização dos informantes da pesquisa}

Obtiveram-se nove informantes pais. Destes, quatro eram o casal e um apenas a mãe. Com idade entre 18 a 24 anos, cinco pais e quatro pais com idade entre 25 a 35 anos.

Obteve-se 19 informantes, profissionais de saúde, destas três enfermeiras, seis técnicas de enfermagem, uma assistente social, duas nutricionistas, três fisioterapeutas, uma psicóloga e três médicas.

$\mathrm{Na}$ análise emergiram temas e subtemas, sendo estes: AMBIENTE DE UTINEONATAL e seus subtemas: Percepção dos pais sobre o ambiente da UTIN, Percepção da equipe de saúde sobre o ambiente da UTIN; AMBIENTE DE CUIDADO: Orientações recebidas pelos pais no momento da internação, Percepção dos profissionais sobre o conhecimento dos pais quanto ao cuidado com o seu filho, Orientações dadas aos pais pela equipe de saúde e metodologia de orientação, Facilidades e dificuldades encontradas ao orientar os pais na UTIN; AMBIENTE RELACIONAL: Relação dos pais com a equipe de saúde.

\section{AMBIENTE FÍSICO DE UTIN}

\section{Percepção dos pais sobre o ambiente da UTIN}

A maioria refere-se ao ambiente como marcado pelas rotinas da unidade, os horários de visita, os profissionais, porém nenhum menciona os sentimentos que geram a internação, como os medos, incertezas, seguem as falas:

"[...] no horário de visitas é liberado o pai e a mãe, só não pode quando tem procedimento, outras pessoas o horário é as 15 ás 15:30 quem informou foi a doutora, as enfermeiras ajudaram, lavar as mãos na entrada e saída, deixar o telefone desligado, se tocar não atender" (P2). 
"Bem no início quando eu cheguei aqui a primeira vez foi a médica que me atendeu, qualquer coisa as enfermeiras o que tu pergunta se elas não respondem elas pedem pra médica responsável, qualquer coisa que tu pergunta para a enfermeira, á como é que ta o neném como é que ela ta indo é com o médico elas não dão...sei que é a médica mas quem é técnico e enfermeiro assim não sei só no crachá" (P5).

O ambiente da UTIN oferece cuidados de alta complexidade e garantia de sobrevida às crianças, apesar de sua importância ser relevante e difundida, este ambiente é temeroso, repleto de muitos ruídos, luzes em constante mudança, assim como a temperatura. Assim o envolvimento da equipe na assistência a esta família, facilita a interação entre os profissionais que por ali passam e executam suas tarefas diárias, facilitando a recuperação do RN pelo envolvimento dos pais dentro do processo de hospitalização (LOUDET et al., 2017).

Em sua primeira visita na unidade, os pais deparam-se com as tecnologias envolvidas no cuidado do seu filho, nestas com frequência visualizam a criança em uma incubadora, com infusão venosa, sondas, respiradores e incubadoras, neste momento a equipe pode fornecer apoio a fim de que estes compreendam o motivo da utilização de todos estes aparelhos para o cuidado (REICHERT; LINS; COLLET, 2007). A enfermagem interligada a família, é capaz de ajudálos a compreender e a enfrentar a dificuldade deste momento, fornecendo um cuidado integral e minimizando o estresse destes pais (SILVA, 2017).

\section{Percepção da equipe de saúde sobre o ambiente da UTIN}

Os informantes referiram que o ambiente da UTI Neo é um ambiente de cuidado de alta complexidade, estressante, de apoio á família em uma unidade tensa. Em relação á permanência dos pais no local refere que se sentem confortáveis sendo que um informante referiu sentir-se desconfortável nos momentos em que são realizados determinados procedimentos no RN que possam ser dolorosos, conforme as falas:

"Uma unidade tensa, na visão dos pais que reporta muito medo." (E1)

"Desconfortável quando é realizado um procedimento que fosse doloroso para o paciente." (E17)

"Mais ou menos, sei que a presença dos pais é muito importante para a criança, porém, em alguns casos, eles atrapalham um pouco, pois acham que alguns cuidados (HGT, punções venosas...) "judiam" a criança e são desnecessários." (E12)

Além do fator ansiedade, esta a relação do cansaço pelo alto grau de exigência do saber técnico e carga de trabalho neste local, as questões de vida e morte iminentes, como também as questões éticas (SILVA, 2017). Desta maneira o ambiente é marcado por fortes emoções, envolvendo desde a família até os profissionais de saúde que prestam atendimento no local, sendo que cada um irá apresentar graus de vulnerabilidade diferentes, necessidades particulares e específicas (RAMÍREZ et al., 2017). 


\section{AMBIENTE DE CUIDADO}

\section{Orientações recebidas pelos pais no momento da internação}

Os pais informam que no momento da internação do seu filho na UTIN, foram comunicados sobre o estado clínico da criança e os cuidados gerais que os pais devem ter no ambiente, como a lavagem das mãos ao entrar na unidade, cuidados com o barulho, conforme falas baixo:

"[...] falou que tava tudo bem que tinha um problema no pulmão, um problema respiratório, no mais tava tudo tranquilo, um pouco de infecção." (P2) dele." (P3)

"A doutora falou o que aconteceu no primeiro momento e as condições físicas

No momento da internação a equipe de saúde tem papel essencial, de minimizar os medos e ansiedades dos pais, proporcionando conforto, responder às preocupações, explicar o estado de saúde, tratamento e equipamentos usados no bebê, com ênfase à criança. À medida que os pais vêm á unidade para outras visitas as informações podem ser complementadas (MOREIRA, 2017).

\section{Percepção dos profissionais sobre o conhecimento dos pais quanto ao cuidado com o seu filho}

A maioria dos informantes refere que percebe os pais cientes quanto ao cuidado oferecido ao seu filho pela equipe, sendo isto possível através do diálogo com os pais, pelos questionamentos e pela participação ativa dos mesmos, conforme falas abaixo:

"Pois na conversa com os mesmos é possível perceber que eles estão cientes do quadro de saúde do bebê, visto que a equipe orienta e esclarece suas dúvidas e anseios diariamente." (E6)

"Na hora da visita, eles nos questionam muitas vezes, sobre várias coisas, quando estão ganhado de peso, quantas vezes ganham dieta etc." (E14)

"As informações específicas do paciente são dadas pelo médico, muitas vezes usam termos técnicos a compreensão se torna limitada. Quanto ás rotinas da unidade e cuidado de enfermagem se percebe que há mais facilidade." (E11)

A humanização do cuidado em um UTIN exige-se uma interação entre os profissionais e destes com a família, como também a garantia de acesso ás tecnologias permitindo segurança do recém-nascido, o acolhimento ao bebê e sua família, proporcionando assim uma UTIN humanizada (MELO, 2017).

Em relação à frequência das orientações aos pais, os profissionais referem orientar todas às vezes:

"Acredito que seja em média uma orientação em função da pouca carga horária." 
"Oriento nos horários de conversa com os pais e quando necessário durante a permanência no hospital." (E9)

\section{Orientações fornecidas aos pais pela equipe de saúde e metodologia de orientação}

Referem que a metodologia utilizada para orientar os pais é o diálogo, escuta sensível e material educativo, como cartazes e folders, seguem respostas:

"Escuta sensível, orientações sociais, encaminhamento para a rede de apoio." (E1)

"Alguns avisos estão dispostos na forma de cartazes na entrada da UTIN e outras orientações são dadas pela equipe de forma verbal. No quarto oferecido para as puérperas há um mural de avisos. Tenho conhecimento que um folder de orientações está sendo elaborado." (E6)

Para compreender a essência do cuidado humanizado, a escuta sensível é tão importante quanto o procedimento técnico, uma vez que nem sempre os conhecimentos técnicos funcionam tão bem diante das situações de estresse (OLIVEIRA; CRUZ, 2017). Há uma necessidade de envolver a família no cuidado, para que possam cuidar da criança após a alta. O profissional de saúde deve reconhecer que é preciso incluir a família no cuidado que desenvolve (SILVA, 2017).

Sobre as orientações fornecidas aos pais pela equipe de saúde, a maioria dos informantes referiu que são sobre rotinas da unidade, tais como cuidados de higiene, lavagem de mãos, dieta, aleitamento materno, diagnóstico e prognóstico e importância do toque, conforme segue:

"Orientação quanto às rotinas da UTIN, cuidados de higiene (lavagem das mãos), horários de conversa de pais com médico plantonista, evolução clínica do paciente (piora ou melhora) prognóstico do paciente." (E9)

"Lavagem das mãos, cuidados com higiene do RN (banho, coto umbilical), controle de sinais vitais (significado dos sinais e suas variações), uso medicação e nutrição." (E10)

O contato dos pais com o bebê, a formação do vínculo e manutenção do mesmo é fundamental durante a internação na UTIN, facilitando o despertar do cuidado com o $\mathrm{RN}$ nos pais e consequentemente auxiliando no processo de recuperação dele (LOUREIRO et al., 2009).

\section{Facilidades e dificuldades encontradas ao orientar os pais na UTIN}

Os informantes referiram como algumas facilidades encontradas ao orientar os pais, a boa aceitação das orientações, a participação no cuidado, a presença na unidade e o vínculo com a equipe. Conforme segue: 
"Mostram interesse em participar e conhecer o processo, a permanência de um responsável durante a internação, a infraestrutura, equipe multiprofissional." (E1)

"Na maioria das vezes estão dispostos a receber orientações e segui-las." (E6)

Em relação às dificuldades nas orientações aos pais, os informantes citaram a ansiedade pelo momento de vida que eles estão passando, o entendimento e assimilação das explicações fornecidas, a superproteção, os horários de trabalho do profissional e o horário em que os pais estão presentes na unidade e a necessidade de um manual de rotinas para os pais. Conforme segue:

"Ansiedade dos pais com relação à doença e internação, pais que permanecem na UTI [...]" (E10)

"Dificuldades de alguns pais no entendimento das explicações (evolução do paciente e estado geral)." (E9)

"Necessitamos de orientações por escrito sobre as rotinas da UTIPED/NEO para ser dado aos pais no momento da internação para que sejam mais facilmente cumpridas." (E8)

O cuidado prestado ao RN e a participação da família neste contexto, é recente, algumas pesquisas que foram realizadas mostram que existe uma ambivalência na relação equipe $x$ família, pois a participação da mãe no cuidado ao mesmo tempo em que importante, essencial, em algumas circunstancia é percebido como algo que lhes atrapalha na execução das tarefas da unidade (OLIVEIRA et al., 2017).

\section{AMBIENTE RELACIONAL}

\section{Relação dos pais com a equipe de saúde}

Nesta categoria a maioria dos informantes referiu que as orientações recebidas foram dos profissionais médicos plantonistas e equipe de enfermagem. Estas informações, na sua maioria, foram sobre o quadro geral dos seus filhos, prognóstico e procedimentos, conforme os discursos abaixo:

"Recebemos informações do neném, tipo hoje ele ta com sonda não ta recebendo nada de alimento, recebemos uma previsão." (P5)

Ao visitarem o seu filho, é importante que os pais identifiquem quem está cuidando da criança no plantão, assim eles se sentirão a vontade para perguntarem sobre os cuidados com a criança, mesmo assim, algumas informações só poderão ser fornecidas pelo médico ou pela enfermeira. O médico é o profissional que irá esclarecer dúvidas, e orientá-los sobre o estado de saúde da criança, possíveis causas da doença e o prognóstico. A equipe de saúde deve ser um elo entre mãe e filho, revelando o estado de saúde da criança e sobre o ambiente de cuidados intensivos (RAMÍREZ et al., 2017). 
Em relação às informações recebidas durante a internação, à maioria ser importante às mesmas, também comentam que na maioria das vezes quem os orientou foi à médica plantonista, conforme fala:

"É bastante importante é uma atenção extra todo cuidado é pouco é um prematuro." (P5)

Neste local é importante que a equipe de saúde acompanhe os pais, principalmente no momento da internação. Para minimizar os sentimentos envolvidos, ansiedade, medos, é papel de a equipe demonstrar-se disponível para conversar e ouvir as dúvidas e preocupações da família (LOPES, 2017).

\section{CONSIDERAÇÕES FINAIS}

A realização deste estudo permitiu conhecer a percepção de pais e equipe de saúde sobre o ambiente de cuidado ao recém-nascido internado numa unidade de terapia intensiva neonatal. Para estes pais o ambiente da UTIN, é percebido como um ambiente de rotinas, com os horários de visita e vários profissionais, porém nenhum deles comentou sobre os sentimentos envolvidos no momento da internação do seu filho, sobre o medo da perda desta criança ou sobre o ambiente confuso e complexo da UTIN.

Os principais dados obtidos com a equipe de saúde, primeiramente foi em relação à percepção sobre o ambiente, a maioria referiu este como sendo de alta complexidade, estressante, de apoio á família e tensa. Em relação à permanência dos pais na unidade, a maioria referiu que se sentem confortáveis e em alguns momentos desconfortáveis quando há algum procedimento, por exemplo.

A percepção do conhecimento dos pais quanto ao cuidado com a criança, para a equipe de saúde os pais estão cientes quanto ao cuidado oferecido ao seu filho. Em relação à interação entre pais e equipe de saúde, os profissionais referem conversar com os pais e orientá-los durante sua permanência na unidade, a frequência das orientações como sendo todas às vezes que necessário alguns referiram que não estão desenvolvendo tal atividade e que no momento é realizada pela assistente social outros referiu não ter contato com os pais.

Quanto à metodologia de orientação, a equipe de saúde referiu como sendo através do diálogo, escuta sensível e material educativo, como cartazes e folders. Tais orientações são sobre rotinas da unidade, diagnóstico e prognóstico. Foi referido por eles que as facilidades encontradas ao orientar os pais, são a boa aceitação das orientações, a participação no cuidado, a presença na unidade e o vínculo com a equipe.

Em relação às dificuldades relatadas pela equipe de saúde nas orientações aos pais, a equipe citou a ansiedade, a falta de entendimento das explicações relacionado ao grau de escolaridade, superproteção dos pais, os horários restritos do profissional que não possibilita o encontro com os pais e a necessidade de um manual de rotinas para os pais. Percebe-se que a 
inclusão dos pais no cuidado do recém-nascido internado na UTIN é tida como uma das dificuldades para a equipe de saúde, pelo modelo de atendimento, pela hegemonia médica, por considerarem o ambiente estressante, isto pode dificultar o reconhecimento pela equipe de saúde, dos pais como parceiros no processo de cuidado.

Pensando em um cuidado humanizado, este estudo tornou evidente o papel exercido pelos profissionais de saúde, no processo de internação do recém-nascido na UTIN, além disto, o quanto o ambiente está diretamente influenciando estes sujeitos, como Florence Nightingale já o mencionava como condicionante e influenciador.

$\mathrm{O}$ que é referido por Florence remete aos achados neste estudo, um dos ambientes de desenvolvimento iniciais da criança. A unidade de terapia intensiva neonatal, através de um cuidado integral poderá facilitar a sua recuperação, como também promover o vínculo entre o recém-nascido e sua família e posteriormente a sua inserção na sociedade.

\section{REFERÊNCIAS}

BARDIN, L. Análise de conteúdo. $3^{\mathrm{a}}$ ed. Lisboa: Edições 70; 2011.

LOPES, L. C. A. Boas práticas no cuidado ao recém-nascido: construção de um guia voltado para a prática. 2017.

LOUDET, C. I.; MARCHENA, M. C.; MARADEO, M. R.; FERNÁNDEZ, S. L.; ROMERO, M. V.; VALENZUELA, G. E.; TUMINO, L. I. Reducing pressure ulcers in patients with prolonged acute mechanical ventilation: a quasi-experimental study. Revista Brasileira de terapia intensiva, v. 29, n. 1, p. 39-46, 2017.

LOUREIRO, L. L. et al. Reações dos pais diante da hospitalização de um recémnascido em UTI Neonatal. LINS - SP, 2009.

MELO, M. D. N. Práticas favorecedoras na atenção qualificada ao recém-nascidouma nova ótica na unidade de terapia intensiva neonatal. 2017.

MOREIRA, M. C. Psicólogo intensivista: reflexões sobre a inserção profissional no âmbito hospitalar, formação e prática profissional. Temas em Psicologia, v. 25, n. 3, p. 1225-1239, 2017.

OLIVEIRA, J. B.; FRANCALINO, T. R.; SILVA, M. L. F.; ARAÚJO JÚNIOR, A. C.; LIMA, L. R. Atuação do enfermeiro no controle de infecção hospitalar em Unidade de Terapia Intensiva (UTI). Mostra Interdisciplinar do curso de Enfermagem, v. 2, n. 2, 2017.

OLIVEIRA, W. R. D.; CRUZ, I. C. Contamination risk in intensive care unit environment (ICU)-systematic literature review for a clinical protocol. Journal of Specialized Nursing Care, v. 9, n. 1, 2017. 
RAMÍREZ, M. T.; PALOMINO, S. R.; TEBEROBSKY, M. V.; ISMAEL, L.; TUMINO, A. L. G.; REINA, R.; ESTENSSORO, E. Diminuição das úlceras por pressão em pacientes com ventilação mecânica aguda prolongada: um estudo quasi-experimental. Rev Bras Ter Intensiva, v. 29, n. 1, p. 39-46, 2017.

REICHERT, A. P. S.; LINS, R. N. P.; COLLET, N. Humanização do cuidado da UTI Neonatal. Revista Eletrônica de Enfermagem - Universidade Federal da Paraíba, v. 9, n. 1, p. 200-213, 2007.

SILVA, S. B. D. Campanha do silêncio na UTI neonatal da Maternidade Nossa Senhora de Nazareth em Boa Vista-RR. 2017.

TOLDO, M. P.; GRAZIOLI, D. S.; HANUER, M. C.; ROSA, A. P.; PRESSI, N. C.; XIRELLO, T.; SOUZA, S. S. Acolhendo familiares e visitantes dos pacientes hospitalizados na UTI geral de um hospital público do oeste catarinense. Anais do SEPE-Seminário de Ensino, Pesquisa e Extensão da UFFS, v. 6, n. 1, 2017. 